\title{
Decontextualized Language Input and Preschoolers' Vocabulary Development
}

\section{Citation}

Rowe, Meredith. 2013. “Decontextualized Language Input and Preschoolers' Vocabulary Development." Semin Speech Lang 34 (04): 260-266.

\section{Published Version}

doi:10.1055/s-0033-1353444

\section{Permanent link}

http://nrs.harvard.edu/urn-3:HUL.InstRepos:13041200

\section{Terms of Use}

This article was downloaded from Harvard University's DASH repository, and is made available under the terms and conditions applicable to Other Posted Material, as set forth at http:// nrs.harvard.edu/urn-3:HUL.InstRepos:dash.current.terms-of-use\#LAA

\section{Share Your Story}

The Harvard community has made this article openly available.

Please share how this access benefits you. Submit a story.

\section{Accessibility}




\section{Decontextualized Language Input and Preschoolers' Vocabulary Development}

Meredith L. Rowe, Ed.D. ${ }^{1}$

\section{ABSTRACT}

This article discusses the importance of using decontextualized language, or language that is removed from the here and now including pretend, narrative, and explanatory talk, with preschool children. The literature on parents' use of decontextualized language is reviewed and results of a longitudinal study of parent decontextualized language input in relation to child vocabulary development are explained. The main findings are that parents who provide their preschool children with more explanations and narrative utterances about past or future events in the input have children with larger vocabularies 1 year later, even with quantity of parent input and child prior vocabulary skill controlled. Recommendations for how to engage children in decontextualized language conversations are provided.

KEYWORDS: Decontextualized language, extended discourse, narrative, vocabulary, input

Learning Outcomes: As a result of this activity, the reader will be able to (1) define decontextualized language; (2) discuss why decontextualized input is challenging and important; (3) list three different types of decontextualized language that parents use with children and provide an example of each; (4) discuss the contexts in which different types of decontextualized language are likely to occur in parent-child interaction.

Much research has focused on the important role that the quantity and quality of linguistic input plays in children's language development. Input quantity, often measured as the number of words parents direct to their children, is positively related to child vocabulary development. ${ }^{1,2}$ Input quality refers to more specific aspects of the input and can be measured in a variety of ways. Two common measures of input quality are the vocabulary
${ }^{1}$ Department of Human Development and Quantitative Methodology, University of Maryland, College Park, Maryland.

Address for correspondence: Meredith L. Rowe, Ed.D., Department of Human Development and Quantitative Methodology, University of Maryland, College Park, MD 20742 (e-mail: mrowe@umd.edu).
Child Language Input and Interaction: Key Concepts for the Speech-Language Pathologist; Guest Editor, Meredith L. Rowe, Ed.D.

Semin Speech Lang 2013;34:187-193193. Copyright (C) 2013 by Thieme Medical Publishers, Inc., 333 Seventh Avenue, New York, NY 10001, USA. Tel: +1(212) 5844662.

DOI: http://dx.doi.org/10.1055/s-0033-1353444.

ISSN 0734-0478. 
diversity of the input and the syntactic complexity of the input; both are found to positively predict child vocabulary development during the early years of language learning. ${ }^{1,3}$ During the preschool years, an additional feature of input quality that is found to be very beneficial for children's vocabulary, narrative, and later reading abilities is the use of decontextualized language.

Decontextualized language, also referred to as extended discourse, is abstract language that is removed from the here and now. ${ }^{4}$ Examples of decontextualized language typically seen in parent input are explanations that tell how things work or why we do things, narrative comments about events that happened in the past or may happen in the future, pretend utterances used during pretend play, and nonimmediate talk during book reading. ${ }^{5}$ Decontextualized language is challenging for children for several reasons. First, because the meaning of decontextualized language is conveyed primarily through the linguistic cues and not through the context, ${ }^{6}$ it requires a more abstract level of analysis by the child than does comprehending contextualized talk that is focused on the here or now, such as object labels. Second, some types of decontextualized language, particularly explanations, tend to focus on cause-and-effect relations that require an understanding of sequencing and causality. Finally, the linguistic nature of decontextualized language is itself more complex. That is, decontextualized language utterances are often longer than contextualized utterances and tend to include more low-frequency or rare vocabulary words, and more complex syntax, such as use of elaborated noun phrases, adverbs, connectives, and mental state verbs. ${ }^{7}$ By the time children are in preschool, they typically have the vocabulary knowledge and cognitive capacity to handle the challenge of decontextualized language. More importantly, exposure to decontextualized language during this period can provide children with practice in the forms of academic language they need to master in school, and helps foster positive language outcomes.

In this article, I review the scant literature on parent use of decontextualized language input and child language development and discuss a recent longitudinal study where we found that decontextualized language input during the preschool years was particularly useful for children's subsequent vocabulary development. In addition to emphasizing the quantity, diversity, and linguistic complexity of talk children are exposed to, it is important to pay attention to the extent to which the input provided by parents, teachers, and therapists is grounded in the here and now versus decontextualized.

Beginning around the preschool years, parents' uses of decontextualized language are associated with children's later vocabulary, narrative skills, and reading comprehension skills. ${ }^{4}$ One of the first areas where parents use decontextualized language with children is through talk during pretend play. Parents' use of pretend utterances during play with 3-year-olds is found to relate to children's later vocabulary comprehension and to their ability to provide formal definitions. ${ }^{8}$ Other forms of decontextualized input include explanatory talk and narrative utterances about past or future events. Beals found relations between both parents' use of explanations and narratives during family mealtimes and children's receptive vocabulary skills at age $5 .^{9}$ She also found relations between parent use of explanations and children's abilities to provide definitions of words, as well as between parent use of narrative utterances and children's story comprehension. Tabors and colleagues found that parental decontextualized talk in low-income homes to children between 3 and 5 years of age predicted the children's narrative production skills at kindergarten, controlling for various other factors, such as family income and parent education. ${ }^{10}$

Studies also show that using nonimmediate talk during book reading has benefits for child language development. Specifically, asking the child to predict what will happen next in a story, and making connections between the story and the child's real life facilitates language development, particularly children's story comprehension, receptive and productive vocabulary skills, and ability to produce formal definitions. ${ }^{11}$ Storytelling itself is an activity that relies on decontextualized language. For example, Curenton and colleagues found that parents' oral storytelling with children contains more 
decontextualized language than book reading. ${ }^{12}$ Other work has examined interventions using different types of input during storytelling. For example, Reese and colleagues compared the effects of training low-income parents in dialogic reading, which focuses on asking children questions during storybook reading, versus elaborative reminiscing, which focuses on asking children questions while engaging them in jointly constructed narratives about previous events. They found that children of parents in the elaborative reminiscing condition made larger gains in narrative skill than did children of parents in the dialogic reading condition. ${ }^{13}$

In sum, previous research suggests clear relations between parents' uses of decontextualized language with 3- to 5-year-old children and the children's vocabulary and narrative skills—skills that are extremely important precursors to literacy development. ${ }^{14,15}$ Further, there is some evidence that it is possible to train parents in using decontextualized language (e.g., narrative), which results in positive outcomes for children's language development. ${ }^{13}$

A recent study examined whether parents change over time in their use of decontextualized language and whether decontextualized language input related to children's gains in receptive vocabulary development. ${ }^{16}$ The study also asked whether relations between decontextualized language and child vocabulary remained when the quantity of parent input is held constant. This is an important question because it is likely that parents who talk more in general with their children use more decontex- tualized language, and it could just be the quantity of input that is driving the relations to improved child outcomes rather than the decontextualized language more specifically.

\section{METHODS}

This study includes 50 children and their primary caregivers who were participating in a larger longitudinal study of children's language development in the greater Chicago area. The families were selected to be representative of the greater area, with the exception that they all spoke English in the home as the primary language. As a result there was diversity in terms of ethnicity and income, and just over half of the children were boys ( 27 of 50 ). The parent-child dyads were videotaped engaging in their ordinary daily activities in their homes for 90 minutes at child ages 18, 30, and 42 months. Parents and children were not restricted to any room or space and were followed around by the research assistant with a handheld video camera. At 42 months, and 1 year later at 54 months, the children were administered the Peabody Picture Vocabulary Test (PPVT) III as a measure of vocabulary comprehension. ${ }^{17}$ All caregiver speech to the child and child speech in the videotaped sessions was reliably transcribed at the level of the utterance and then all utterances were reliably coded as to whether or not they were decontextualized. Decontextualized utterances fell into three main categories: pretend, explanation, and narrative as described in Table 1 . We also coded nonimmediate talk during book

Table 1 Definition and Examples of Categories of Decontextualized Utterances

\begin{tabular}{|c|c|c|}
\hline$\overline{\text { Category }}$ & Definition & Example \\
\hline Explanations & $\begin{array}{l}\text { Talk that requested or made logical connection } \\
\text { between objects, events, concepts, or } \\
\text { conclusions }\end{array}$ & $\begin{array}{l}\text { "Because the lights have to be on for the } \\
\text { remote to work." }\end{array}$ \\
\hline Pretend & $\begin{array}{l}\text { Talk during pretend episodes of interaction } \\
\text { including making an object represent another; } \\
\text { attributing actions, thoughts, or feelings to } \\
\text { inanimate objects; assuming a role or persona; } \\
\text { enacting scripts or routines }\end{array}$ & $\begin{array}{l}\text { "We have to have the police come and } \\
\text { make an accident report now." }\end{array}$ \\
\hline Narrative & $\begin{array}{l}\text { Talk about events that happened in the past or } \\
\text { will happen in the future }\end{array}$ & $\begin{array}{l}\text { "He is going to look in your nose and your } \\
\text { throat and your ears." }\end{array}$ \\
\hline
\end{tabular}


reading (e.g., asking children to make predictions about what happens next in a story or making connections between the story and the child's life), but there were too few of these utterances to include them as their own category so we included them with the narrative utterances.

\section{RESULTS}

Parents varied in how much they used decontextualized language and their use of decontextualized language increased over time as children got older. Fig. 1 shows that at 18 months only $2.2 \%$ of parent utterances were decontextualized whereas at 42 months 9.4\% were decontextualized. Looking at the raw numbers of specific types of decontextualized talk as shown in Table 2, we see that parents increased in their use of all three types of talk and that variation in parents increased as well. For example, by 42 months the average parent used 30 narrative utterances during the interaction, yet the range was from 0 to 220 . This sample of parents was diverse in regard to socioeconomic status, yet parent education was not as strongly related to parent use of decontextualized language as it was to quantity of parent input. Specifically, parent education was positively related to input quantity, or the number of words parents used with children $(r=0.36, p<0.05)$, and to the number of parents utterances that were explanations $(r=0.32, p<0.05)$, yet education was not related to parents uses of narrative or pretend utterances.

Children varied in their vocabulary comprehension as measured by the PPVT standardized scores. At 42 months the average score was 106.2 (standard deviation $[\mathrm{SD}]=17.4$ ) and at 54 months the average score was 110.4 (SD $=18.2$ ). At 54 months there were two children who did not complete the PPVT, thus the following analysis is based on a sample size of 48 children.

We examined relations between parent use of decontextualized language input at child age 42 months and children's vocabulary 1 year later at 54 months as measured on the PPVT. Parents who used more narrative utterances $(r=0.42, p<0.01)$ and parents who used more explanations $(r=0.36, p<0.05)$ with their 3-and-a-half-year-olds had children with larger PPVT scores 1 year later. There was no association between use of pretend utterances and child vocabulary. We then ran partial correlations controlling for parent education, the child's prior PPVT score at 42 months, and the total number of words that the parents spoke during the interaction. This analysis tells us about the relation between parent use of decontextualized language on the gains children make in vocabulary in a year, with the quantity of parent talk held constant. We found that the previous relations were still statistically significant: Parents who used more narrative utterances had children with larger PPVT scores $(r=0.34, p<0.05)$, and parents who

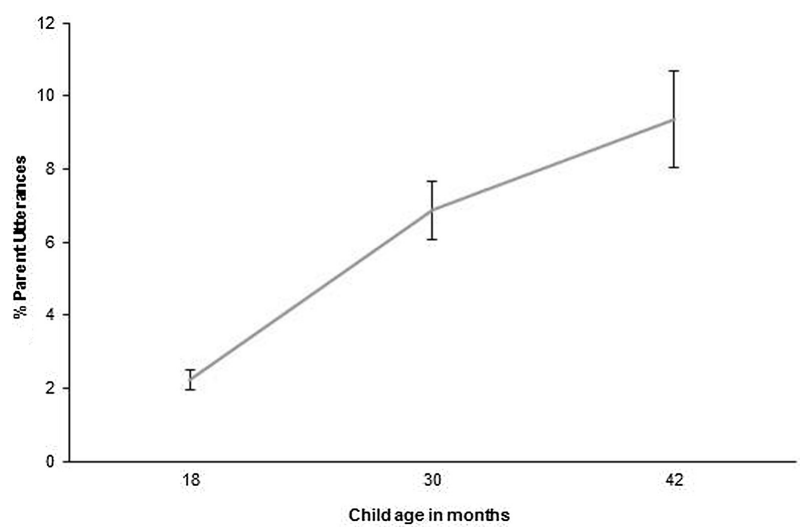

Figure 1 Change over time in proportion of parent utterances that are decontextualized $(n=50)$. 
Table 2 Mean Number of Decontextualized Language Input Utterances during 90-min Interactions at Child Ages 18, 30, and $42 \mathrm{mo}(n=50)$

\begin{tabular}{|c|c|c|c|}
\hline & $18 \mathrm{mo}, \mathrm{M}$ (SD) Range & 30 mo, M (SD) Range & $42 \mathrm{mo}, \mathrm{M}$ (SD) Range \\
\hline Explanation & $10.0(8.9) 0-46$ & 12.7 (10.2) 0-39 & 13.3 (10.0) 0-45 \\
\hline Pretend & 8.0 (17.5) 0-85 & 32.9 (54.8) 0-264 & 49.7 (113.9) 0-637 \\
\hline Narrative & $6.4(11.2) 0-85$ & 23.7 (41.1) 0-258 & $30.3(42.2) 0-220$ \\
\hline
\end{tabular}

$\mathrm{M}$, mean; SD, standard deviation.

used more explanations had children with larger PPVT scores $(r=0.29, p<0.05)$. Thus, over and above the quantity of parent talk, the use of decontextualized language predicts child vocabulary, controlling for the child's previous vocabulary skill. In sum, spending more time talking about the past and future and providing causal explanations for how things work and why they happen contributes to children's vocabulary development during this time.

\section{DISCUSSION}

In the current study, at child age 42 months, an average of approximately $10 \%$ of parent utterances with children are decontextualized utterances, yet parents vary in how often they use this type of challenging talk with children. Variation in parent use of decontextualized language relates to later child vocabulary skill, even with quantity of talk, parent education, and previous child vocabulary skill controlled. Thus, parents who talked more with their children about events that happened in the past or will happen in the future and parents who provide their children with more explanations for how things work and why things are, had children with larger vocabularies 1 year later than parents who produced less narrative and explanatory talk.

These findings are comparable to previous work within a low-income sample showing a link between parental narrative utterances and explanations during mealtimes with 5-year-olds and children's vocabulary skill, ${ }^{9}$ yet the current results control for quantity of talk as well. As discussed earlier, narratives and explanations are challenging for children to understand, as they require thinking abstractly about content; making logical connections between objects, events, concepts, or conclusions; and they often employ more challenging linguistic structures. ${ }^{7,9}$ Nonetheless, our results indicate that in this diverse sample in regard to socioeconomic status, 3-and-a-half-year-olds are not too young to understand explanations about how things work in the world, or conversations about previous or future events, and that indeed this type of challenging, decontextualized talk might be just what they need to help facilitate vocabulary acquisition further at this age.

One factor that may be playing a role here that we did not examine is the effect of the child. For example, some children may be better able to engage in conversations about the past and future or may elicit more explanations from their parents by asking more why questions, or by just being more interested in how things operate in the world. Thus, it is unclear if parents produce more explanations on their own initiative or because of characteristics of their children, or both. With respect to parental narrative style, previous research has documented individual differences in parents' abilities to elicit narratives from children and shows that in general, parental narrative behavior predates and correlates with children's narrative performance. ${ }^{18-22}$ Thus, by exposing children to narrative discourse, parents can provide their children with experience engaging in conversations about topics removed from the here and now and scaffold their children's ability to produce narrative discourse themselves. ${ }^{23,24}$ This previous work was more recently confirmed by the experimental study discussed earlier by Reese and colleagues showing that engaging children in elaborative reminiscing (e. g., narrative talk) promotes children's narrative development more than engaging them in joint book reading. ${ }^{13}$ In the current study parent decontextualized talk related to child vocabulary skill. Providing children with narrative and 
explanatory talk draws heavily on children's knowledge of vocabulary. Thus, it is not surprising that using these types of discourse more frequently can promote children's vocabulary development.

\section{IMPLICATIONS}

Parents increase over the early childhood period in their use of decontextualized language with their children, and by the preschool years this variation in parents' use of narrative and explanatory talk predicts the gains children make in vocabulary. Thus, encouraging parents to engage in decontextualized language is important and has the potential to increase children's vocabulary skill (as shown in the current study) as well as children's own narrative skill and reading comprehension as shown in previous research. ${ }^{9,13}$ It is important for parents, teachers, and therapists to understand that preschoolers can handle this type of challenging talk and that there are simple ways to engage children in decontextualized language conversations. Some suggestions are as follows:

- Engage in pretend play with children.

- Answer children's why questions.

- Start conversations about things the adult and child did together in the past "Remember when we went to the show last week?" or "Remember the game we played last time you were here at therapy?" and prompt the child to elaborate on the conversation "What was your favorite part?"

- Start conversations about future events and ask the child to make predictions "Grandma is coming to visit soon. What do you think she will want to do while she is here?"

- Read a book with the child and draw connections to the child's life: "The boy in the story is going to the dentist, just like you went to see the dentist when you had a cavity last month. What do you remember about your dentist visit? Is it similar to the story?"

- Read a book with the child and ask the child to make predictions "What do you think is going to happen next?"

It is clear from the previous literature that parents tend to use different types of decontex- tualized talk during different contexts. Not surprisingly, play seems to elicit pretend utterances, meals elicit narrative and explanatory talk, book reading elicits both contextual (e. g., reading) talk and nonimmediate talk, and oral storytelling or elaborative reminiscing elicits decontextualized talk (e.g., narrative) as well. Thus, in thinking about how to work with parents to promote their decontextualized language input, or in thinking of settings in which teachers or therapists might engage children in decontextualized conversations, one area of focus should be context. It will likely be easier to engage children in talk about the past or future if children are provided with prompts about things they care about such as places they have visited, birthday or holiday experiences, their friends, and so on. These types of conversations can occur naturally in situations such as mealtimes, or other periods where there is no focus on a specific book or toy play. Further, book reading should be encouraged, but with specific emphasis on incorporating nonimmediate talk, specifically thorough discussing how the story relates to the child's own experiences or by asking the child to make predictions about what might happen next in the story.

Providing preschool children with decontextualized language input offers them practice in the forms of abstract discourse they will be expected to master in school in the core curriculum, and helps them to develop their oral language abilities. Importantly, these oral language abilities (e.g., vocabulary, narrative, story comprehension) are strong predictors of children's later ability to learn to read. ${ }^{25,26}$ Thus, in addition to providing children with a large quantity of input and input that is diverse in vocabulary and syntactically complex, it is important to make sure that children have the opportunity to engage in conversations around decontextualized language during the preschool years to pave the way for their academic success.

\section{ACKNOWLEDGMENTS}

This research was supported by grants from the National Institute of Child Health and Human Development: K99/R00HD055522 to the author, and P01HD40605 to Susan GoldinMeadow. I thank the participating families for sharing their child's language development 
with us; the research assistants on the Language Development Project at the University of Chicago for help in collecting and transcribing the data, Christine Bascetta for coding, and Kristi Schonwald and Jason Voigt for administrative and technical assistance.

\section{REFERENCES}

1. Huttenlocher J, Haight W, Bryk A, Seltzer M, Lyons T. Early vocabulary growth: relation to language input and gender. Dev Psychol 1991;27:236-248

2. Hart B, Risley TR. Meaningful Differences in the Everyday Experience of Young American Children. Baltimore, MD: Brookes Publishing; 1995

3. Hoff E. The specificity of environmental influence: socioeconomic status affects early vocabulary development via maternal speech. Child Dev 2003; 74:1368-1378

4. Snow CE, Tabors PO, Dickinson DK. Language development in the preschool years. In: Dickinson DK, Tabors PO, eds. Beginning Literacy with Language: Young Children Learning at Home and School. Baltimore, MD: Brookes Publishing; 2001:1-25

5. Dickinson DK, Tabors PO, Eds. Beginning Literacy with Language: Young Children Learning at Home and School. Baltimore, MD: Brookes Publishing; 2001

6. Cummins J. Linguistic interdependence and the educational development of bilingual children. Rev Educ Res 1979;49:222-251

7. Curenton SM, Justice LM. African American and Caucasian preschoolers' use of decontextualized language: literate language features in oral narratives. Lang Speech Hear Serv Sch 2004;35:240-253

8. Katz JR. Playing at home: the talk of pretend play. In: Dickinson DK, Tabors PO, eds. Beginning Literacy with Language: Young Children Learning at Home and School. Baltimore, MD: Brookes Publishing; 2001:53-73

9. Beals D. Eating and reading: links between family conversations with preschoolers and later language and literacy. In: Dickinson DK, Tabors PO, eds. Beginning Literacy with Language: Young Children Learning at Home and School. Baltimore, MD: Brookes Publishing; 2001:75-92

10. Tabors PO, Roach KA, Snow CE. Home language and literacy environment: final results. In: Dickinson DK, Tabors PO, eds. Beginning Literacy with Language: Young Children Learning at Home and School. Baltimore, MD: Brookes Publishing; 2001:111-138

11. DeTemple JM. Parents and children reading book together. In: Dickinson DK, Tabors PO, eds.
Beginning Literacy with Language: Young Children Learning at Home and School. Baltimore, MD: Brookes Publishing; 2001:31-51

12. Curenton SM, Craig MJ, Flanigan N. Use of decontextualized talk across story contexts: how oral storytelling and emergent reading can scaffold children's development. Early Educ Dev 2008; 19:161-187

13. Reese E, Leyva D, Sparks A, Grolnick W. Maternal elaborative reminiscing increases low-income children's narrative skills relative to dialogic reading. Early Educ Dev 2010;21:318-342

14. Anderson RC, Freebody P. Vocabulary knowledge. In: Guthrie JT, ed. Reading Comprehension and Education. Newark, DE: International Reading Association; 1981:77-117

15. Cunningham AE, Stanovich KE. Early reading acquisition and its relation to reading experience and ability 10 years later. Dev Psychol 1997; 33:934-945

16. Rowe ML. A longitudinal investigation of the role of quantity and quality of child-directed speech in vocabulary development. Child Dev 2012; 83: 1762-1774

17. Dunn LM, Dunn LM. Peabody Picture Vocabulary Test, 3rd ed. Circle Pines, MN: American Guidance Service; 1997

18. Fivush R, Fromhoff FA. Style and structure in mother-child conversations about the past. Discourse Process 1988;11:337-355

19. Haden CA, Haine RA, Fivush R. Developing narrative structure in parent-child reminiscing across the preschool years. Dev Psychol 1997; 33:295-307

20. McCabe A, Peterson C. Getting the story: a longitudinal study of parental styles in eliciting oral personal narratives and developing narrative skill. In: McCabe A, Peterson C, eds. Developing Narrative Structure. Hillsdale, NJ: Erlbaum; 1991 217-253

21. Peterson C, McCabe A. A social interactionist account of developing decontextualized narrative skill. Dev Psychol 1994;30:937-948

22. Snow CE, Dickinson DK. Social sources of narrative skills at home and at school. First Lang 1990; 10:87-103

23. Bruner JS. Children's Talk: Learning to Use Language. New York, NY: Norton; 1983

24. Vygotsky LS. Mind in Society: The Development of Higher Psychological Processes. Cambridge, MA: Harvard University Press; 1979

25. Snow CE. The theoretical basis for relationships between language and literacy in development. J Res Child Educ 1991;6:5-10

26. Snow CE, Burns MS, Griffin P, Eds. Preventing Reading Difficulties in Young Children. Washington, DC: National Academies Press; 1998 